\title{
In memoriam: B. E. Christopher Nordin
}

\author{
M. Horowitz ${ }^{1} \cdot$ H. Morris ${ }^{2}$
}

Published online: 20 June 2015

(C) International Osteoporosis Foundation and National Osteoporosis Foundation 2015

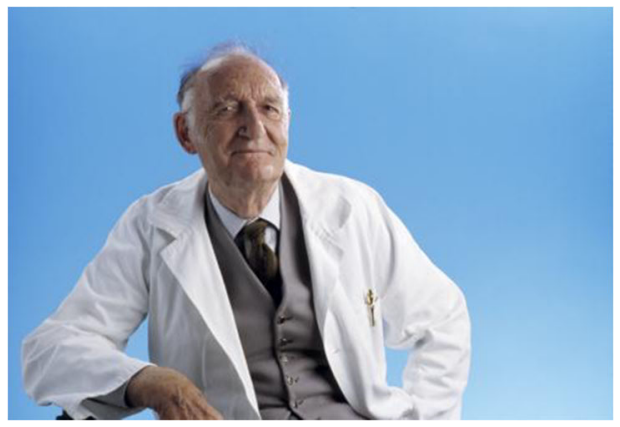

Chris Nordin, a pioneer in the field of bone and calcium metabolism, was born in England of Swedish parents and worked as a translator for the British Legation in Stockholm during the Second World War. However, he saw a career in medical science as offering a genuine chance to make a useful contribution to the community. At the Hammersmith Postgraduate Medical School, research on renal physiology, particularly phosphate and calcium metabolism, was the catalyst for his future work. He simplified a renal index of phosphate

On behalf of Allan Need (Adelaide), Ego Seeman (Melbourne), Richard Prince (Perth), John Eisman, Markus Seibel (Sydney), and J. Chris Gallagher (Omaha)

This obituary was first published in Journal of Mineral and Bone Research (Vol. 30, No. 6, June 2015, pp 949-950; DOI: 10.1002/jbmr. 2505) and is reproduced here by kind permission of Wiley and the American Society for Bone and Mineral Research.

H. Morris

Howard.Morris@health.sa.gov.au

1 School of Medicine, University of Adelaide, Adelaide, Australia

2 SA Pathology, Adelaide, Australia excretion, a topic that formed the basis for a doctorate thesis, and subsequently applied this idea to the interpretation of simultaneous blood and urine samples, thereby avoiding troublesome timed clearances. While at the Hammersmith he asserted that vitamin D deficiency alone caused osteomalacia and calcium deficiency alone caused osteoporosis. The boldness and apparent clarity of this idea was the springboard for his future career.

He continued his training in New York and then Glasgow, publishing many manuscripts and in 1964 was invited by the Medical Research Council to become Director of the newly created MRC Mineral Metabolism Unit in Leeds. This was a major honor, reflecting his growing reputation within the medical research establishment. The task was to unravel the pathophysiology of renal stone disease, a poorly understood cause of considerable morbidity. His strategy was to gather large amounts of clinical data and search for patterns using computerized methods. A database comprising over 700 subjects presenting to a Renal Stone Clinic was generated and analysis and interpretation of these data was pivotal to the modern understanding of renal stone disease.

He led a staff of some 40 clinicians, scientists, and technicians in Leeds devoted to the study of calcium physiology. In the case of stone disease, it became clear that hypercalciuria was predominantly absorptive, rather than renal as then believed, and ion products explained the stone disease types. Many of the analyses were developed within the Unit. The aforementioned plasma-urine relationship was an essential tool for understanding the renal component of the calcium economy. As well he pioneered a calcium absorption test, later encouraging the development of a model for small intestinal absorption. The methodology of balance studies was improved. A technique of particular interest was the isotopic mineral apposition rate, which, combined with calcium balances, also estimated bone resorption. At the time there was 
no agreement on how tracer calcium results should be interpreted for estimating bone formation. Insights from a team involving physicists and physiologists provided a logical analysis later substantiated using histomorphometry. Bone studies in renal disease provided another model to test ideas using histomorphometry, radiology, and isotopically determined formation rates.

The pathophysiology of bone loss was always dear to his heart and again, the Unit used a clinical approach. Using concepts concerning bone remodeling, he confirmed the importance of the menopause in osteoporosis investigating the role of sex hormones in maintaining the calcium economy. The findings were among the first to suggest that postmenopausal osteoporosis was due to bone resorption in excess of bone formation. The department was one of the first to struggle with the measurement of bone morphology and develop forearm densitometry.

Chris recognised that vitamin D deficiency and hip fractures were associated. This was later found to be the case even in South Australia, despite the more generous sunlight than enjoyed in Leeds. In 1981 he resigned as Director of the MRC Unit and moved to Adelaide where he began a long collaboration with physicians at the Professorial Units at the Royal Adelaide Hospital as well as clinical biochemists of the Institute of Medical and Veterinary Science. He was passionate about the translation of research to reduce the burden of fractures; he established a Department of Health committee to alert medical practitioners and nursing homes of the need for calcium and vitamin D supplements for the elderly; he argued for general access to densitometry to enable a rational approach for fracture prevention to be undertaken.

The notion of dietary calcium deficiency as a cause of bone loss and osteoporosis and the definition of calcium requirement formed one of his passions and the basis of many research endeavors. He showed that the small rise in plasma calcium at the menopause reflected the complexed calcium fraction rather than ionized calcium and therefore was not driven by parathyroid hormone. This rise in the complexed fraction of plasma calcium accounted for only a part of the known rise in urine calcium, the remainder depending on reduced tubular reabsorption.

Chris published 508 papers and nine books in a career spanning 60 years. Outstanding among many awards is the Officer of the Order of Australia, two Doctorates of Science (Leeds, Adelaide), and the Frederick C Bartter Award from the American Society for Bone and Mineral Research. He cofounded (with Fred Pautard) the journal Calcified Tissue Research (later Calcified Tissue International) and established the European Calcified Tissue meetings. He shifted the osteoporosis paradigm progressively from one with limited clinical application to one where a link between the disease and calcium deficiency was recognized, which resulted in various treatments to restore calcium balance.

Chris had an extraordinary presence, he was Shakespearian in stature, obstinate but vulnerable like King Lear, a provocateur like Puck; he was eloquent and concise in his speech, always confident and always direct to the microphone, so quick to see flaws in logic or methodology. He was a giant intellect and fun to be with at a dinner table. He inspired hard work and creative thinking among many to whom he provided sustained mentorship and enlivened countless scientific meetings. He continued publishing up until recently, co-editing a book launched in May 2014, often quoting Noel Coward: "work is more fun than fun". Despite his prodigious scientific output and his work in improving the lot of patients he had a close and supportive network of friends and family. Although devastated by the loss of his wife Margie in 2000, he later remarried another outstanding partner, Mary, herself a towering intellect. He had a faith which he held privately and enormously enjoyed being among his Quaker Friends. At his funeral on November 6, 2014, in Adelaide, several hundred people joined in a time of recollection. He was buried at the beautiful Unitarian Cemetery in the Adelaide Hills, close to his first home in Adelaide. 